\title{
PREDICTING FOREIGN EXCHANGE USING DIGITAL SIGNAL PROCESSING
}

\section{Robinson Mbato ${ }^{1}$ and Kabari Ledisi G. ${ }^{2}$} \author{
Nigeria. \\ ${ }^{1}$ Email: robinson.mbato@m-rinternational.com \\ ${ }^{2}$ Email: ledisigiokkabari@yahoo.com
}

Computer Science Department, Ignatius Ajuru University of Education, Port Harcourt,

Cite this article:

Robinson M., Kabari L.G. (2021), Predicting Foreign Exchange Using Digital Signal Processing. British Journal of Computer, Networking and Information Technology 4(2), 1-11. DOI: 10.52589/BJCNITSQWFNRND.

\section{Manuscript History}

Received: 15 July 2021

Accepted: 24 Aug 2021

Published: 5 Sept 2021

Copyright $\left({ }^{\circ} 2020\right.$ The Author(s). This is an Open Access article distributed under the terms of Creative Commons AttributionNonCommercial-NoDerivatives 4.0 International (CC BY-NC-ND 4.0), which permits anyone to share, use, reproduce and redistribute in any medium, provided the original author and source are credited.
ABSTRACT: The forex market is one associated with so much volatility and can lead to grave financial losses if not properly understood. To understand the market is to study the price patterns from previous years or months and make predictions from the rate of falling and rising. There have been so much researches aimed at developing a predictive model for the FOREX market, however, no model has been able to handle the market volatility while predicting future rates accurately. In this work, we have developed a digital processing model for predicting foreign exchange using ARIMA and Artificial Neural Network algorithms. We used price datasets for five currencies namely: USD, Swiss Pounds, Yen, Euro and Franc, gotten from the Central Bank of Nigeria (CBN) website. The data ranged from a period of 20 years. The model was simulated using MATLAB software. The study performed excellently in terms of time (26 seconds) and minimal errors (0.7). This work could be beneficial to FOREX traders and to the entire research community.

KEYWORDS: Foreign Exchange, Digital Signal Processing, Forex Traders, Forex Market, CBN 


\section{INTRODUCTION}

The price data of the stock market changes almost every second. The market is a very complicated and challenging system where people will either gain a lot or lose almost everything they have if proper investment decisions are not taken [1]. These decisions are influenced by the price data. This is the reason why the prediction of the stock market price is very important.

The stock market deals on the trading of foreign exchange also called FOREX. FOREX is the trading of currencies in the international market, and this trade is always on 24 hours a day, with prices shooting up and down every second [2]. This market is highly unpredictable and associated with a lot of volatility [3].

There are several techniques that can be employed to achieve this prediction such as using different machine learning algorithms like the Artificial Neural Networks and Autoregressive Integrated Moving Average (ARIMA) time series. ARIMA is applied to the FOREX historical dataset.

Sentiment analysis is also a good way of predicting the future price of a certain currency or currencies by mining the opinion of people from various social platforms such as Twitter, Facebook, yahoo mail etc. and classifying the opinion to get the next probable price.

However, in this study, digital signal processing in financial signals will be carried out in order to make the best estimation of the movement of stock prices. ANN will be used to train the data to recognize price patterns and handle uncertainties in the financial market. ANN is also combined with the ARIMA model to build a forecasting model to predict data points. We are also adopting a classification model called Naïve Bayes Classifier to classify the price data were gotten from the dataset into the four daily observed rates such as "Open", "Close", "Low" and "High".

The main challenge that has been noticed in the prediction of price data or foreign exchange is the lack of a model that can predict accurately despite the serious volatility of the market. This is why we have adopted machine learning algorithms such as the ARIMA time series.

The aim of this study is to develop a digital signal processing model for predicting future stock market prices. To achieve our aim, we: -

i. Develop a hybrid prediction model using ANN and ARIMA algorithms.

ii. Train the model using ANN techniques for six currencies including the Naira.

iii. Test the model using historical price data of the six currencies.

iv. Implement using PYTHON programming language and SPSS data analysis tool. 


\section{RELATED WORKS}

Several kinds of research over the years have been channeled to this field of FOREX prediction using various techniques or a combination of techniques. This section briefly reviews some of the works carried out by these researchers and their limitations.

Nayak et al [1] proposed prediction models for the Indian stock market. They built two prediction models using supervised learning algorithms to handle the daily and monthly predictions. They also combined historical prices with sentiments. They obtained about $70 \%$ accuracy using the supervised learning attributes. When they investigated the correlation between the prices of two months, they discovered that the trends for the months had the least correlation to each other.

However, the scope of their model was narrow and it could not be applied to other currencies.

Basheer et al [2] presented FOREX daily trend prediction using machine learning techniques. The prediction was posed a binary classification problem which stated whether the currency was high or low. SVM and bagging tree feature selection was combined with five feature selection techniques to find the best feature subsets. Also, a percentage normalized profit function (PNP) is invented which shows the ratio between the profit based on the predicted trends and that using ideal predictions. However, the model could only predict for one currency at a time, making it unrobust.

Modi et al [3] presented big data analysis in stock market prediction. An approach for the analysis and understanding of the volatility of stock prices was described and was used to predict its behaviour if invested. They also developed a methodology for the approach using data collection and machine learning algorithms. They concluded that using SVM, Gaussian Kernel and regularization produced better results.

Rehman et al [4] proposed foreign exchange rates prediction using Cartesian Genetic Programming (CGP) and recurrent neural network (RNN). CGP was the algorithm deployed for the prediction model. Trends in the historical data were utilized to predict the future prices of five currencies against the Australian Dollar for the next 1000 days and they obtained an accuracy of $98872 \%$ when evaluated with statistical metrics. However, the implementation of this research was not clearly demonstrated in their research.

Islam et al [5] presented a review on recent advancements in the FOREX currency prediction. They provided a comprehensive review of the researches carried out recently in FOREX especially those from 2017 to 2019. They adopted the keyword search approach to filter the relevant papers for their review. From their review, they discovered that neural networks, pattern-based approaches and optimization techniques were the key techniques adopted by researchers for this purpose. However, they failed to cover other methods which could be used to achieve this feat.

Awoke et al [6] proposed bitcoin price prediction and analysis using deep learning models. They utilized the Long-Short-Term memory (LSTM) and the gated recurrent unit (GRU) to handle bitcoin volatility and predict its future price. However, their model was evaluated poorly using only a few parameters whose performance cannot be generalized. 
Pant et al [7] proposed RNN-based Bitcoin price prediction by Twitter Sentiment analysis. Tweets of Bitcoin were collected from several news accounts and classified into negative and positive sentiments. The percentages of the classification were fed into the RNN with the historical price data and used to predict the price for a particular time frame. The classification accuracy was $81.39 \%$ while the overall accuracy using RNN was $77.62 \%$. However, the accuracy of the model was low and might cause losses if investment decisions are based on it.

Urang and Kabari [8] proposed cryptocurrency prediction using a digital signal processing model. The accuracy of ARIMA is a linear model and GARCH as a non-linear model for the prediction of Bitcoin was evaluated using different statistical forecasting evaluation criteria. The R software was used to carry out this analysis. From the results obtained they concluded that the ARIMA model was better than the GARCH model

Douglas and Kabari [9] presented digital signal processing for predicting stock prices in the financial markets. They developed a model to predict stock market prices and transaction trends to understand the nature and volatility of the market and predict its behaviour to make a profit.

Garg and Vishwakarma [10] proposed an efficient prediction of share price using data mining techniques. They used several data mining classifiers on the stock historical data sets to give recommendations on investment decisions. They discovered from their results that a larger historical data set will yield better prediction results. However, they failed to evaluate their model to ascertain its performance.

\section{METHODOLOGY}

The FOREX data was gotten from the Central Bank of Nigeria repository in the form of a CSV file. The dataset contained the buying price in Naira $(\mathrm{N})$, central price and selling price of five for currencies (USD, YEN, EURO, SWISS FRANC and POUNDS STERLING). A sample of the data is shown in Figure 1. The price data were collected from a range of 20 years i.e. 2001 to 2020. A larger dataset will facilitate better training results, hence our choice of data.

MATLAB was the simulation software used in the training of the data. The data was divided into two parts, the input data which consisted of the buying rate for the currencies and the central Naira rate. The second data was the selling rate which was labelled the target data.

In the MATLAB workspace, 2 variables were created named "train price" and "predicted price". Then the neural network toolbox was used to train the data. The input and target data were imported and a new network canned "net" was created as the neural network. The hidden layer assigned the value of 8 neurons, and the Feedforward model was used for the training.

With an epoch set to 1000 , the number of errors set to 100 , the data was trained. The input values were in 2 rows, hence represented as 2 inputs while the output value was a single row, hence represented as 1. Figure 1-9 give a more descriptive detail of the simulation process. 
British Journal of Computer, Networking and Information Technology

ISSN: $2689-5315$

Volume 4, Issue 2, 2021 (pp. 1-11)

www.abjournals.org

\begin{tabular}{|r|r|r|r|}
\hline Buying Rate & Selling Rate & \\
\hline 379 & 379.5 & 380 \\
\hline 517.335 & 518.0175 & 518.7 \\
\hline 465.2604 & 465.8742 & 466.488 \\
\hline 430.2906 & 430.8583 & 431.426 \\
\hline 3.6775 & 3.6823 & 3.6872 \\
\hline 379 & 379.5 & 380 \\
\hline 515.8948 & 516.5754 & 517.256 \\
\hline 465.1846 & 465.7983 & 466.412 \\
\hline 428.2486 & 428.8136 & 429.3785 \\
\hline 3.675 & 3.6798 & 3.6847 \\
\hline 311.8395 & 379.5 & 380 \\
\hline 464.3129 & 512.5148 & 513.19 \\
\hline 427.283 & 464.9255 & 465.538 \\
\hline 3.6565 & 427.8467 & 3.614 & 3.6662 \\
\hline 379 & 379.5 & 380 \\
\hline
\end{tabular}

Figure1: Dataset of FOREX prices(Source: www.CBN.com)

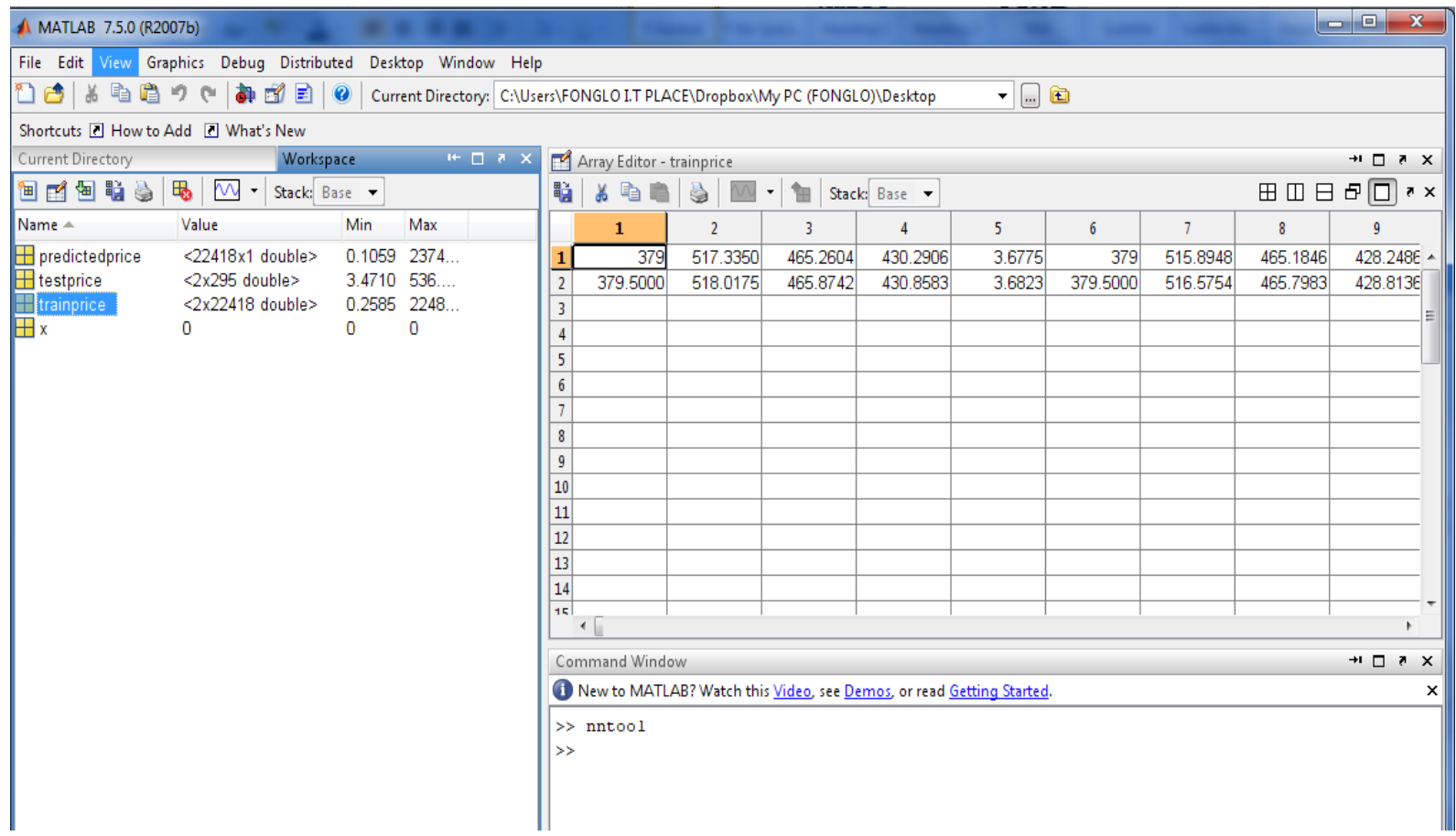

Figure 2: MATLAB Workspace and Array Editor 
British Journal of Computer, Networking and Information Technology

ISSN: $2689-5315$

Volume 4, Issue 2, 2021 (pp. 1-11)

www.abjournals.org

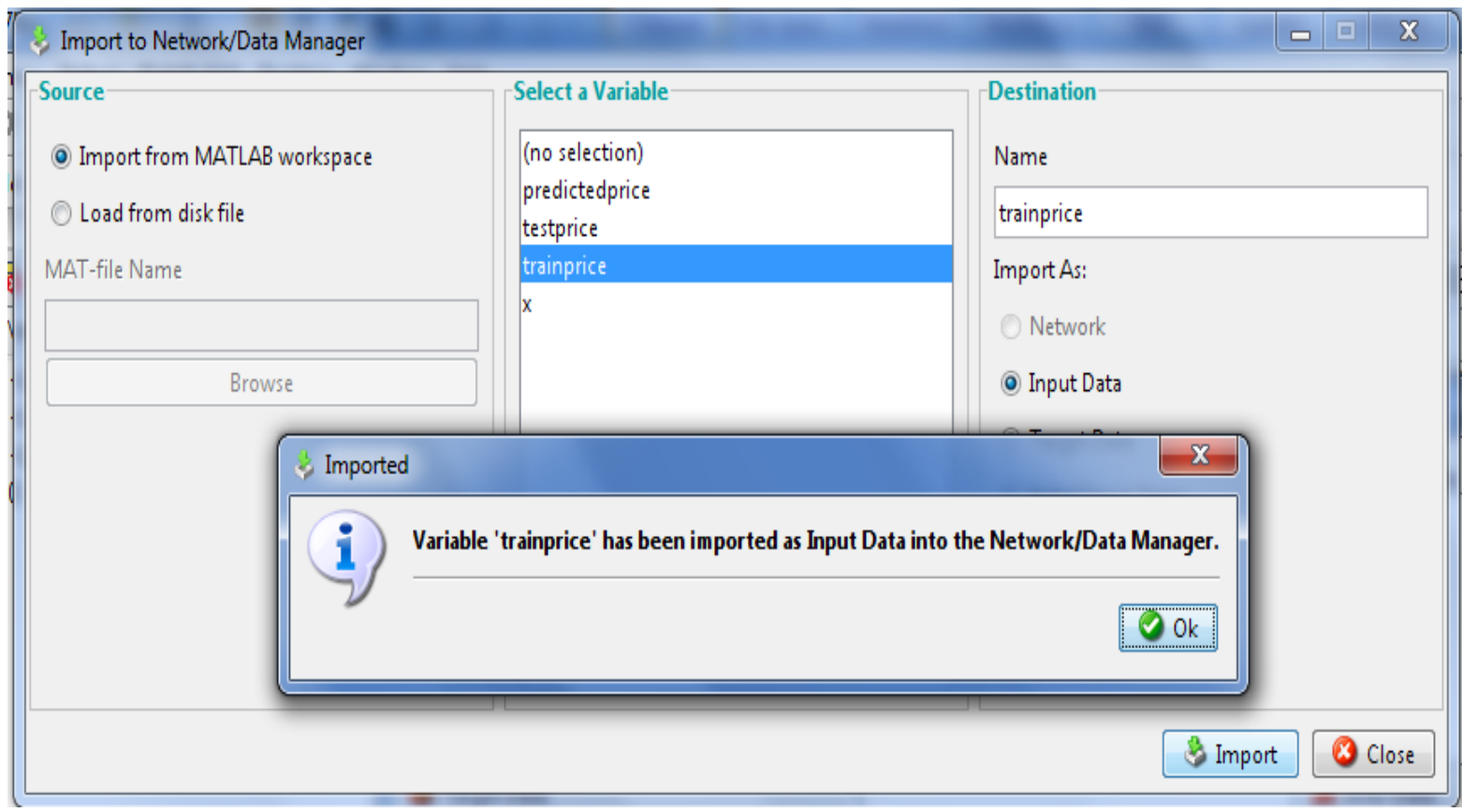

Figure 3: Data Import to the Neural Tool

Neural Network Training (nntraintool)

마 23

Neural Network

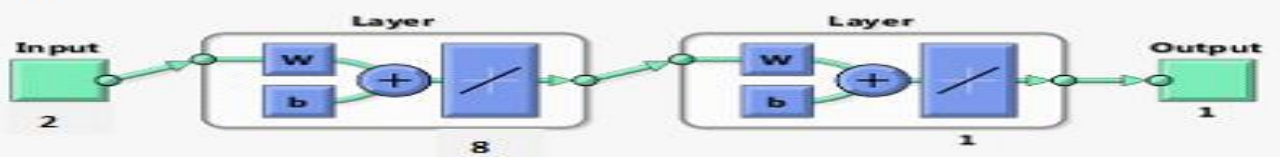

Algorithms

Data Division: Training Only (drvidetrain)

Training: Gradient Descent with Mom

Performance: Mean Squared Error (mse)

Calculations: MEX

Progress

Epoch:

Time:

Performance:

Gradient:

Validation Checks:

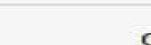

o

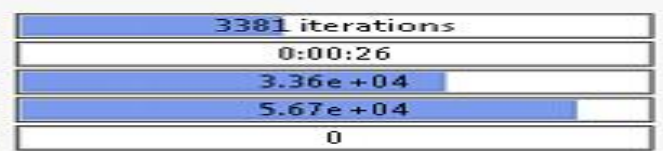

1000

$1.00=-25$

$1.53 e+06$

$8.91 e+07$

$1.00=-05$

Plots

Performance (plotperform)

Training State (plottrainstate)

Regression (plotregression)

Plot Interval: $\square$

1 epochs

CSy Training neural network.

Figure 4: Neural Network for Training the Data 


\section{RESULTS AND DISCUSSION}

After the data was successfully trained in 1000 iterations, the data was used for the prediction of the future rates of the currencies. The test data was loaded using the "load" function and assigned to variable Y. The MATLAB predict function was then used with "mdl", "Xnew" as arguments to draw the plot for each currency.

The test data was broken down into five different currencies and each of the currencies and their value was assigned to $\mathrm{Y}$ during its prediction, in order to draw the plot. The plots are shown in the figures below. The plots consist of the actual prices and the predicted prices.

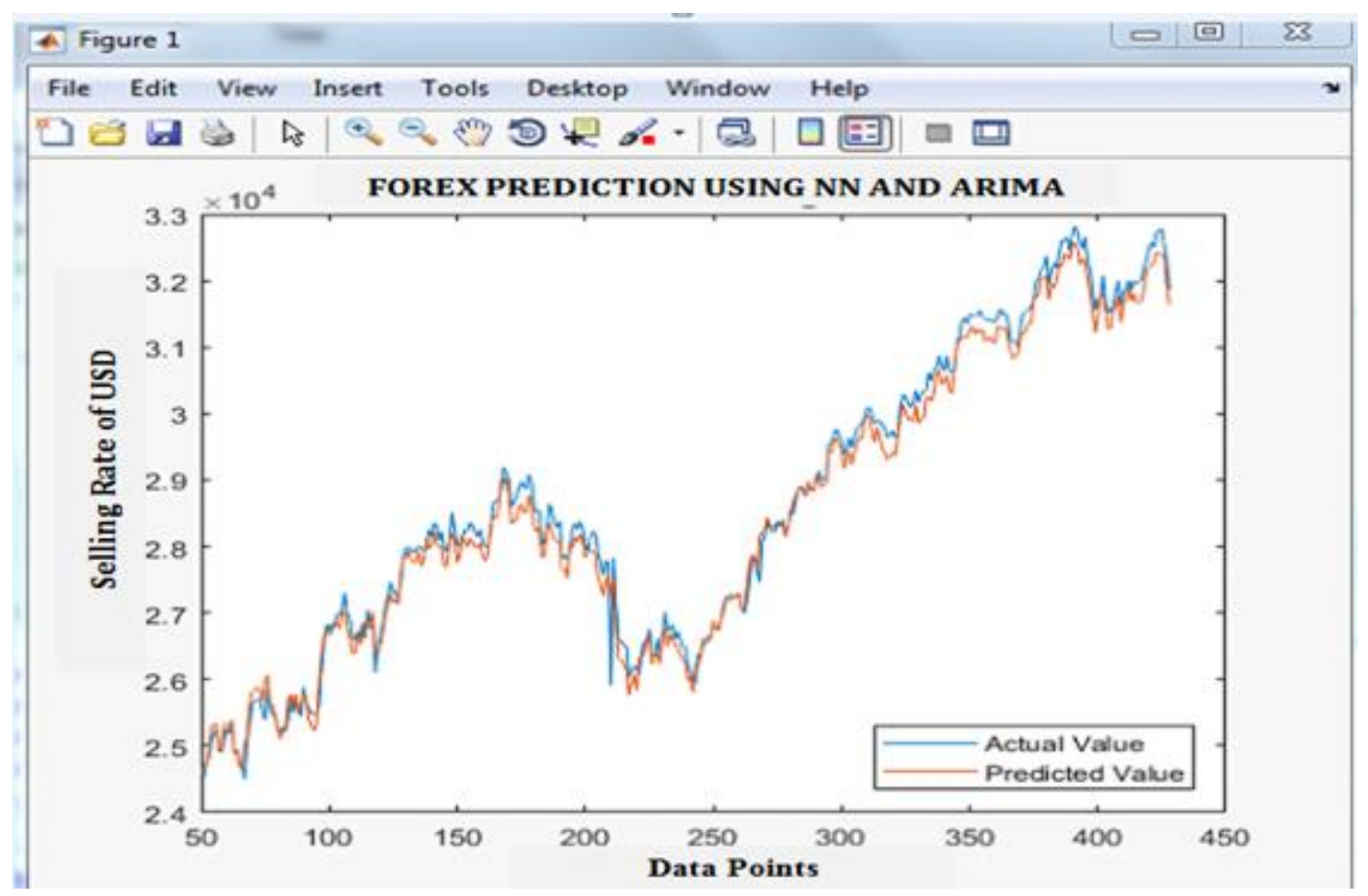

Figure 5: Prediction Plot for USD against Naira 
British Journal of Computer, Networking and Information Technology

ISSN: $2689-5315$

Volume 4, Issue 2, 2021 (pp. 1-11)

www.abjournals.org

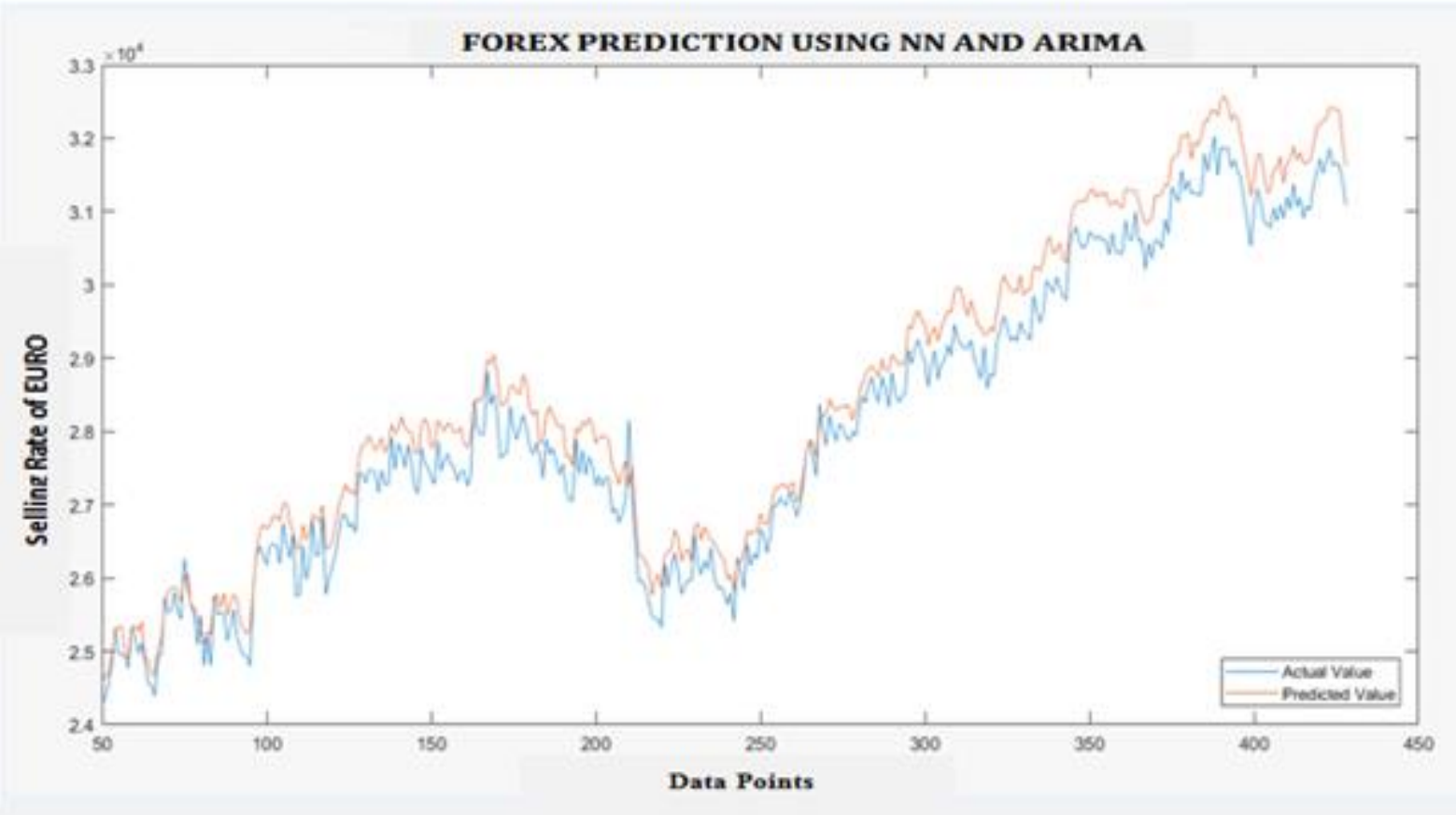

Figure 6: Prediction Plot for EURO against Naira

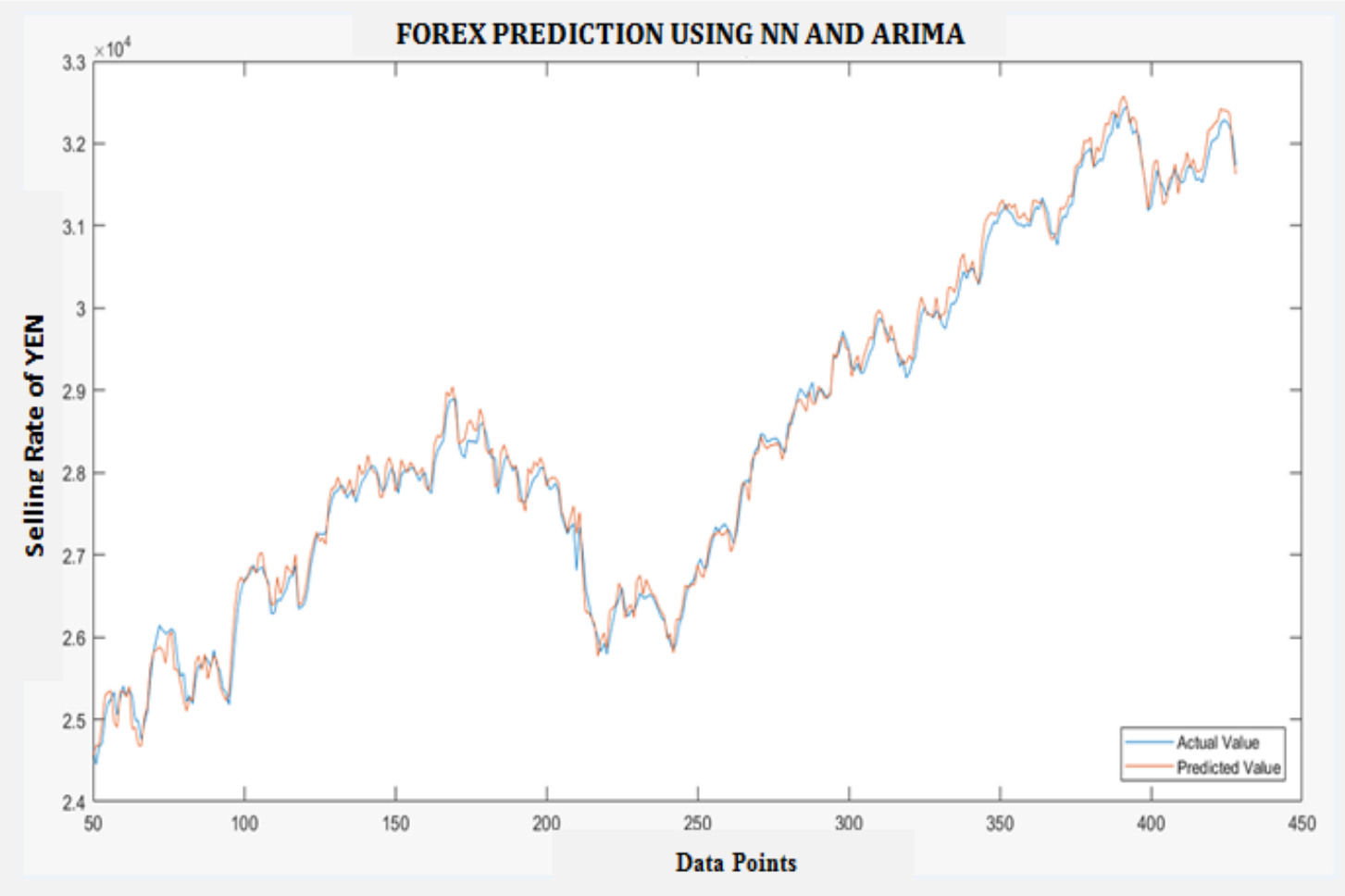

Figure 7: Prediction Plot for YEN against Naira 


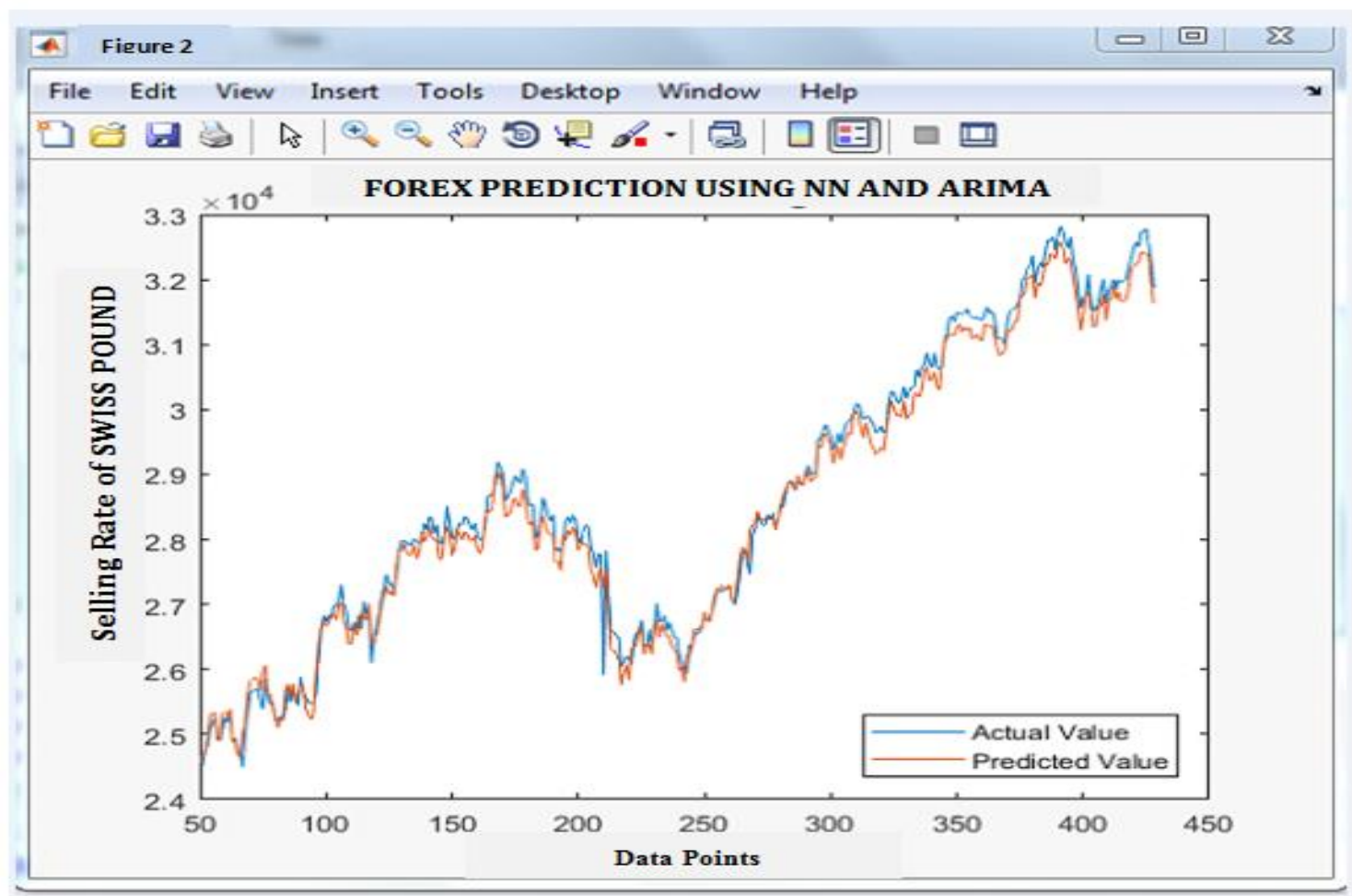

Figure 8: Prediction Plot for SWISS POUNDS against Naira

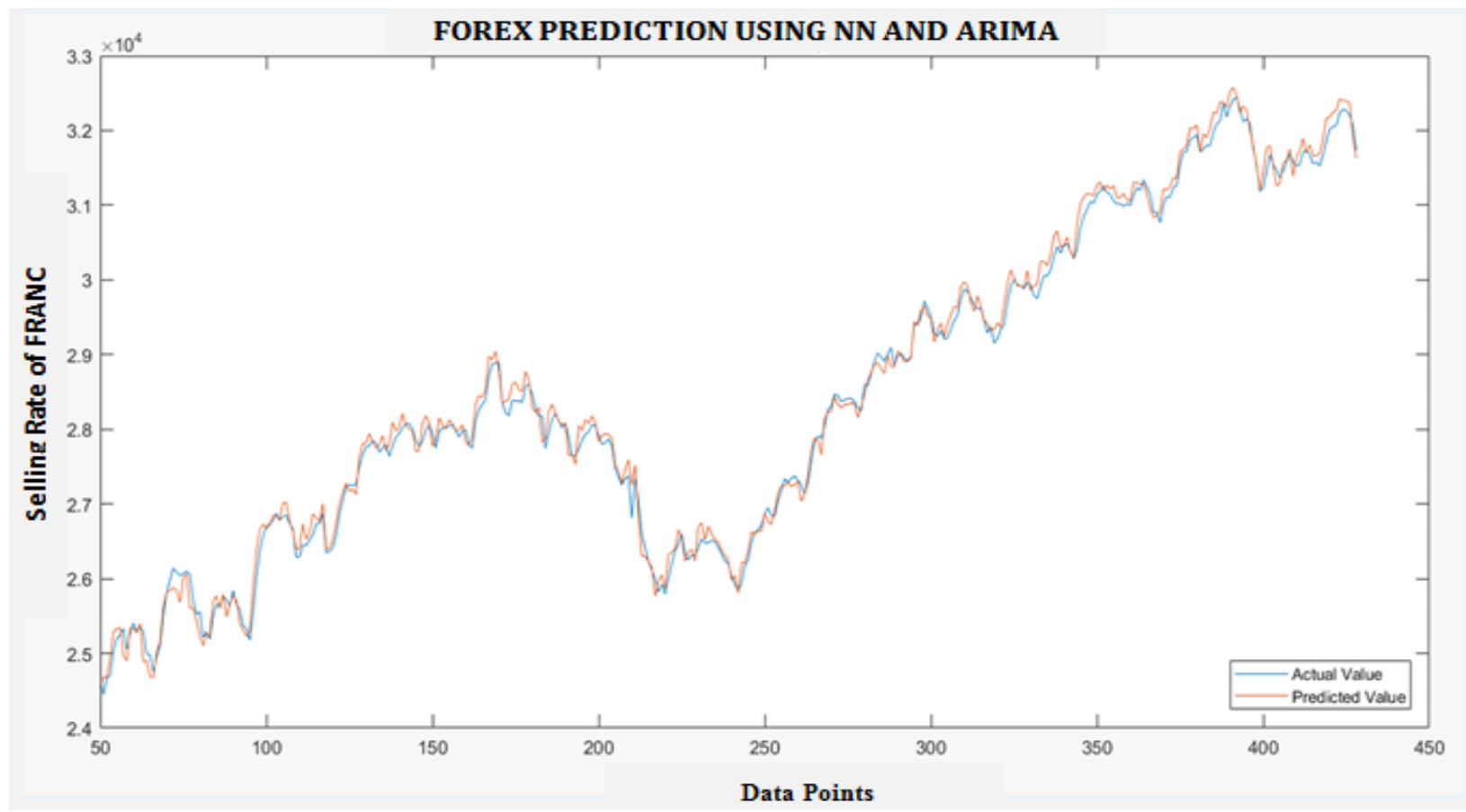

Figure 9: Prediction Plot for SWISS FRANC against Naira 


\section{Table 1: Naïve Bayes Classification Output}

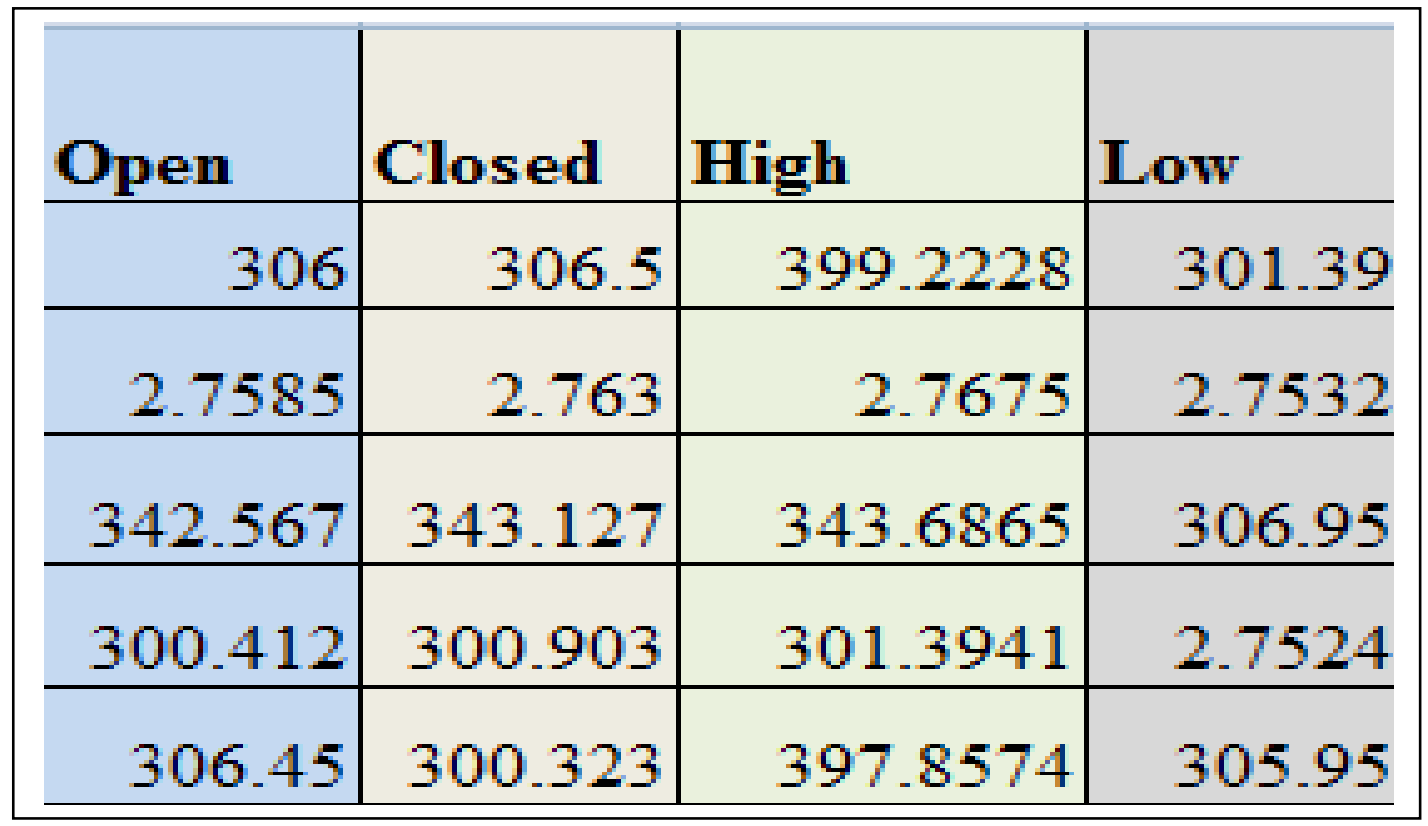

\section{CONCLUSION}

We have developed a FOREX prediction model using hybrid Neural Network and ARIMA models. The model trained the data in 26 seconds which outperforms other models with more training and testing time periods. The model also recorded a minimum training error given by the Root Mean Square Error (RMSE) of 0.7. From the overall performance of our system and the plots shown in our results, it can be discovered that our predictions are closely corresponding to the actual prices. This, therefore, implies an accurate prediction.

\section{REFERENCES}

[1] A. Nayak, M. M. M. Pai and R. M. Pai. "Prediction Models for Indian Stock Market". Twelfth International Multi-Conference on Information Processing. Vol. 89, pp. 441449.

[2] A. Basheer, and M. W. Fakhr. "FOREX Daily Trend Prediction using Machine Learning Techniques." 2011.

[3] P. Modi, S. Shah and H. Shah. "Big Data Analysis in Stock Market Prediction." International Journal of Engineering Research and Technology (IJERT). Vol. 8, No. 10. Pp. 384-386.

[4] M. Rehman, G. M. Khan and S. A. Mahmud. "Foreign Currency Exchange Rates Prediction using CGP and Recurrent Neural Network." Elsevier. Vol. 10, pp. 239244. 2014. 
[5] S. Islam, E. Hossain, A. Rahman, M.S. Hossian and K. Andersson. "A Review on Recent Advancements in FOREX Currency Prediction." Algorithms. Vol. 13, No. 186, pp. 1-23. JUL. 2020

[6] T. Awoke, M. Rout, L. Mohanty and S. C. Satapathy. "Bitcoin Price Prediction and Analysis using Deep Learning Models.” Springer. Vol. 134, pp. 631-640. 2021

[7] R. D. Pant, P. Neupane, A. Poudel, A. K. Pokhrel and B. K. Lama. "Recurrent Neural Network Based Bitcoin Price Prediction by Twitter Sentiment Analysis". IEEE Open Access. Pp. 1-6. 2018.

[8] A. S. Urang and L. G. Kabari. "Cryptocurrency Prediction Using Digital Signal Processing." Journal of Environmental Science, Computer Science and Engineering and Technology. Vol. 9, No. 1, pp. 46-57. DEC. 2019.

[9] M. T. Douglas and L. G. Kabari. "Digital Signal Processing for Predicting of Stock Prices in the Financial Market." Journal of Environmental Science, Computer Science and Engineering and Technology. Vol. 9, No. 2, pp. 196-203. MAR. 2020.

[10] P. Garg and S. K. Vishwakarma. "An Efficient Prediction of Share Prices using Data Mining Techniques." International Journal of Engineering and Advanced Technology (IJEAT). Vol. 8, Issue 9. Pp. 3110-3115. AUG. 2019. 